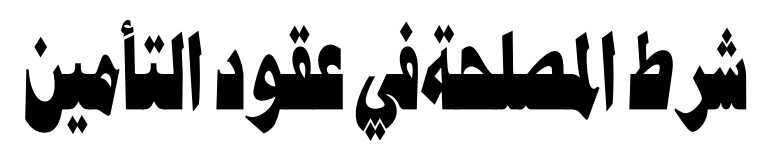

دراست ِِّ القانون الأردني والقانون المصري
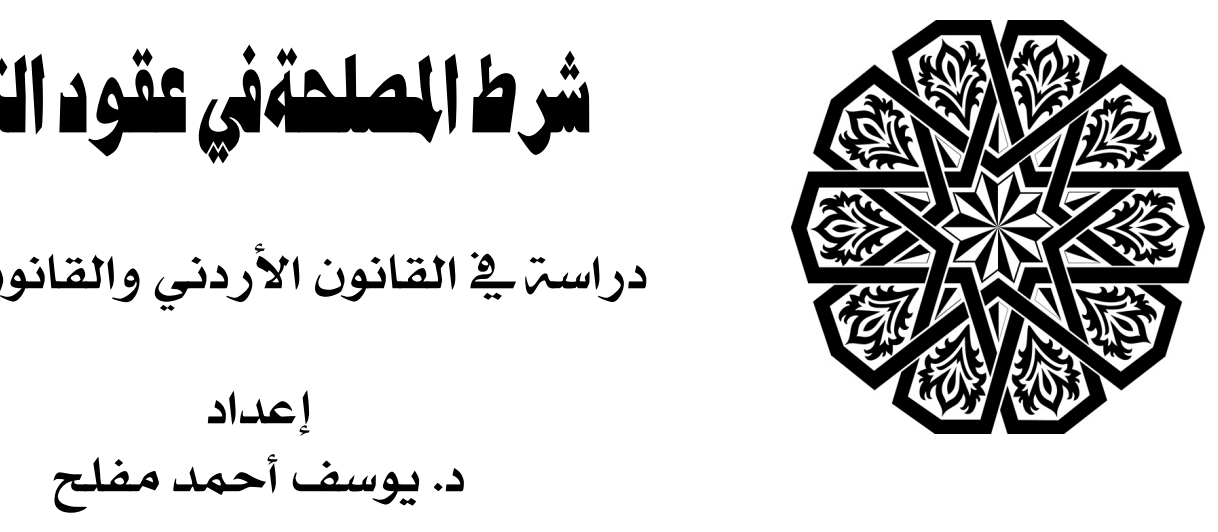

قسم القانون الخاص - جامعة الأهلية

\section{ملخص البحث}

يتناول هذا البحث مسألة تكمن أن المشرع الأردني لم ينص على اشتراط المصلحة في

عقود التأمين وإنما أخضعها للمبادئ العامة التي تحكم العقود المدنية بشكل عام.

وتضمن البحث دراسة نظرية المصلحة في عقود التأمين بالشكل العام ومن ثم البحث في

شرط المصلحة في عقود التأمين على الأشخاص وذلك من حيث وقت المصلحة وصورها

وطبيعتها وثم البحث في شرط المصلحة بعقود التأمين من الأضرار من حيث طبيعتها

وشخص المؤمن له ووقت اشتراطها وذلك في القانون المدني الأردني ومقارنة ذلك بالقانون

$$
\text { المصري وللوصول إلى النتائج والتوصيات. }
$$




\section{Summary}

\section{Interest Clause in Insurance Contracts}

\section{A study in the Jordanian Law}

This research deals with a question that the Jordanian legislator did not provide the requirement of interest in insurance contacts, which it is subject to the general principles governing civil contracts in general.

This study deals with interest theory in insurance contracts in general, then it deals with the interest clause in insurance contracts for persons, in terms of time and nature of the interest clause, then it deals with the interest in contracts insurance for damages required. All these matters will be discussed in the Jordanian Civil Code and comparing it with Egyptian law. In order to reach to best results and recommendations. 
إن عقود التأمين ذات أهمية كبيرة في ظل انتشارها بين أفراد المجتمع وهي علاقة بين طرفين تنقلب إلى مقامرة إذا لم يكن لكل طرف مصلحة يهدف لتحقيقها وتكون مشروعة قانونًا من ذلك لابد من وجود مصلحة واهتم الفقه بالبحث في مفهوم هذه المصلحة ويمكن تعريف المصلحة التأمينية: الحق القانوني في التأمين الناشئ من علاقة مالية قانونية بين الشخص والشيء وموضوع التأمين ويجب أن يكون الهدف من هذه المصلحة جبر الضرر الذي قد يصيبه إذا ما لحق بذلك الشخص أو الشيء أي ضرر '‘. ويمكن استخلاص شروطها بما يلي:

1. أن تكون مصلحة مادية في الملك أو رابطة قانونية ولا عبرة للمصلحة المعنوية إلا في حالة واحدة هي رابطة الدم في تأمين الأشخاص. r. أن تكون مصلحة مشروعة قانونتًا حيث كل لا يصح التأمين على أموال أو أشياء غير قانونية كالتأمين على الأموال والأشياء المسروقة. r. أن تكون المصلحة جدية وأن تكون حالة وقت إبرام العقد أما إذا كانت مصلحة محتملة فلا تكون جدية.

\section{وأجمع الفقه على ضرورة وجود المصلحة التأمينية لعدة أسباب وهي:} أولاً: الحد من مؤثرات الخطر الأخلاقي وذلك لعدم إلحاق الضرر بمال وحياة الغير. ثانيًا: لمنع المقامرة أو المراهنة فيها. ثالثًا: لقياس حجم الخسارة الفعلية.

(1) د. عبد الرزاق السنهوري، الوسيط في شرح القانون المدني، الجزء السابع، عقود الضرر وعقد التأمين، مششأة

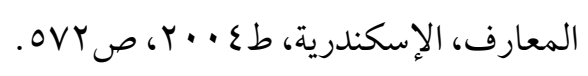




\title{
حدود الدراسة:
}

إن حدود الدراسة هي القانون الأردني مقارنة ببعض القوانين العربية الأخرى كالقانون المصري.

\section{أهمية الدراسةي:}

إن عقود التأمين ذات أهمية اقتصادية واجتماعية وأصبحت مطلبًا لجميع العلاقات التجارية والمدنية وإن عدم وجود المصلحة في عقود التأمين يجعلها تدخل ضمن عقود المقامرة. - مان

\section{مشكلة الدراسة:}

إن مشكلة الدراسة تكمن في أن المشرع الأردني لم ينص على اشتراط المصلحة في عقد التأمين وإنما أخضعها للمبادئ العامة التي تحكم العقود المدنية بشكل عام. المنهج المتبع:

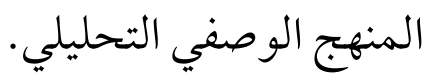
أقساهم الدراسة:

\author{
التمهيد. \\ المبحث الأول: نظرية المصلحة في عقود التأمين \\ المبحث الثاني: شرط المصلحة في عقود التأمين على الأشخاص \\ المبحث الثالث: شرط المصلحة في عقود التأمين من الأضرار

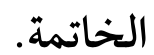




\section{المبحث الأول \\ نظرية المصلحة التأمينية في عقود التأمين}

اختلف الفقه المعاصر في شرط المصلحة في عقود التأمين اتجاهين اثنين أولهما يرى أن

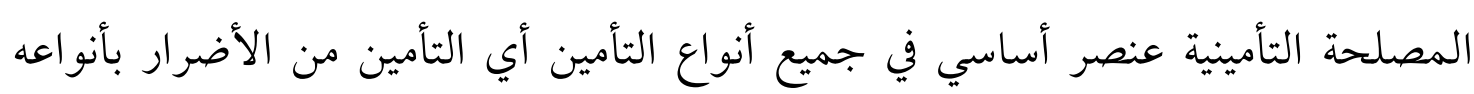
العديدة والتأمين على الأشخاص بأشكاله المختلفة' '. أما الجانب الثاني فقد رأى أن المصلحة التأمينية عنصر واجب توافره في التأمين من

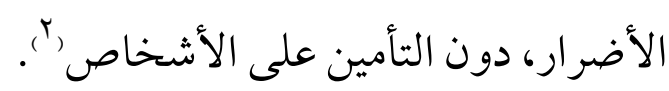
وقد رأى الجانب الثاني في اشتراطه للمصلحة في عقود التأمين من الأضرار دون التأمين على الأشخاص أن المصلحة المشترطة هي مصلحة اقتصادية وذلك استناداً إلى ما جاء في نصوص القوانين الفرنسة والمصرية وبذلك فإنها غير ممكنة التوافر في عقود التأمين على

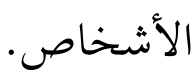

أما الجانب الأول فقد رأى أن المصلحة في عقود التأمين واجبة التوافر في عقود التأمين من الأضرار وعقود التأمين على الأشخاص على حد سواء، بل أن توافرها في عقود التأمين على الأشخاص أكثر أهمية من توافرها في عقود التأمين من الأضرار”ّاّ. والحالة هذه عندما يكون المؤمن له شخصكً غير الشخص المؤمن على حياته، فيكون انعدام المصلحة في هذا النوع

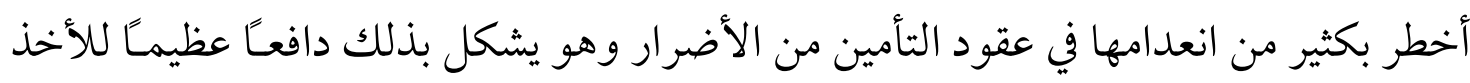
بحياة المؤمن على حياته. موقف المشرع الأردني: عرف القانون المدني الأردني عقد التأمين في المادة ( • ب ه) منه بأنه:

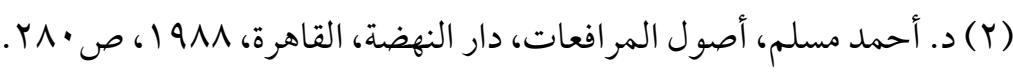

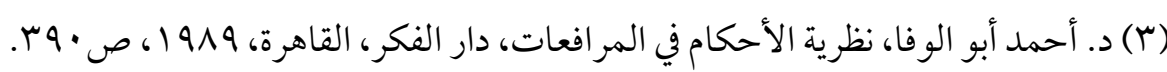


"عقد يلتزم به المؤمن أن يؤدي إلى المؤمن له أو إلى المستفيد الذي اشترط التأمين لصالحه مبلغتًا من المال أو إيراد مرتبًا أو أي عوض مالي آخر في حالة وقوع الحادث المؤمن ضده أو تحقيق الخطر المؤمن في العقد وذلك مقابل مبلغ محدد أو أقساط دورية يؤديها المؤمن له للمؤمن"'('، وجاءت أحكام محكمة التمييز تنظم المصلحة وفق الأحكام العامة الواردة بالقانون حيث جاء نص القرار رقم (·rON) لسنة 10 ·. تقام الدعوى ممن يملك حق بإقامتها وممن له مصلحة قائمة فيها يقرها القانون وذلك وفقـًا لنص المادة ب/ ا من قانون أصول المحاكمات المدنية.

من خلال التعريف نجد أن المشرع الأردني كان موفقَّ في تعريفه هذا من حيث إبرازه لأطراف عقد التأمين، ومسألة القسط المالي المتوجب أداءه من قبل المؤمن له، ومع ذلك فإن هناك عدة ملاحظات على هذا التعريف وهي: أولاً: لم يتطرق المشرع في التعريف للتأمين لحال البقاء:

قيد المشرع أداء المؤمن مبلغ التأمين المتفق عليه للمؤمن له في حالتين اثنتين فقط هما وقوع الحادث المؤمن ضده أو تحقيق الخطر المؤمن في العقد. وبناءً على ذلك فقد أخرج المشرع من نطاق التعريف نوعَّا هامَّا من أنواع التأمين ألاوهو التأمين لحال البقاء، وهو عقد يلتزم المؤمن بمقتضاه بأن يدفع مبلغتً من المال للمؤمن له إن بقي هذا الأخير على قيد الحياة

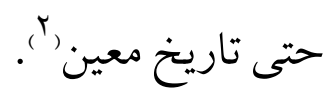
وبالرجوع إلى نص المادة (1) (9) من القانون المدني الأردني: "يلتزم المؤمن في التأمين على الحياة بأن يدفع إلى المؤمن له أو إلى المستفيد المبالغ المتفق عليها عند وقوع الحادث 
المؤمن منه أو حلول الأجل المنصوص عليه في العقد دون الحاجة لإثبات ما لحق المؤمن له

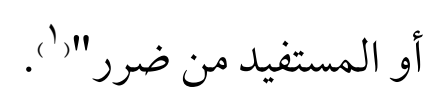

ومن خلال هذه المادة نجد أن المشرع الأردني يفترض وجود صورتين من صور التأمين على الحياة، الثاني منهما هو التأمين لحال البقاء وهو القاضي بأداء المؤمن له مبلغ التأمين المتفق عليه عند حلول الأجل المنصوص عليه في العقد أي حلول الأجل ببقاء المؤمن له حيًا حتى ذلك التاريخ. ثانيًا: إغفال المشرع الأردني لشرط المصلحة في عقود التأمين: من خلال نصوص المواد المتعلقة بعقد التأمين في القانون المدني الأردني نلاحظ أن

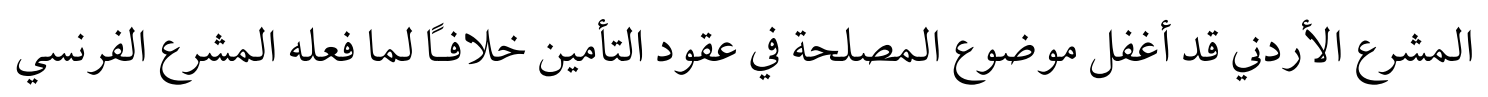
و المصري حيث ما نص القانون المدني المصري في المادة (V) (V) في الأحكام العامة للتأمين أن يكون محلاً للتأمين كل مصلحة اقتصادية مشروعة تعود على الشخص من عدم وقوع خطر معين.

وموضوع المصلحة في عقود التأمين من المواضيع الحساسة في عقود التأمين كونها تثير الكثير من التساؤلات والإشكالات. واشتراط المصلحة في التأمين أمراً تفرضه اعتبارات

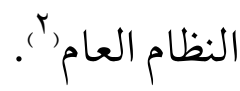
ونلاحظ أن القانون المدني الأردني لم ينص صراحة توافر شرط المصلحة في التأمين في جميع أنواع التأمين وصورها”.

$$
\begin{aligned}
& \text { (1) القانون المدني الأردني. }
\end{aligned}
$$

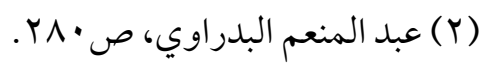
(r) عبد القادر العيسى، دار الثقافة، عمان، 1990 1، ص17 11 . 
ويرى الباحث أن شرط المصلحة يجب أن يتوافر في جميع أنواع التأمين بخلاف ما أتى به الفريق الثاني من اقتصار اشتراطها على عقود التأمين من الأضرار إلا أنني لا أؤيد الفريق الأول في رأيه بأن المصلحة الأدبية أو المعنوية كالمصلحة الاقتصادية''. ولابد من توافر الشروط الموضوعية في المصلحة وهي: أولاً: أن تكون المصلحة مشروعة غير مخالفة للنظام العام والآداب العامة. ثانيًا: أن تكون المصلحة جدية. ثالثًا: أن تكون المصلحة لطالب التأمين المؤمن له. رابعًا: أن تكون المصلحة موجودة وتكون مستمدة من موافقة المؤمن على حياته على جعل عقد التأمين ضامنًا للخطر الذي يهدده.

خامستً: أن تكون المصلحة اقتصادية ويتحقق ذلك عندما تكون متحققة من بقاء المؤمن على

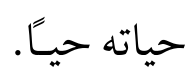




\section{المبحث الثاني \\ شرط المصلحة في عقود التأمين على الأشخاص الثيأ}

من المتفق عليه أن لا يشترط تو افر المصلحة عند إبرام الشخص عقد تأمين على حياة نفسه، حيث تعتبر تلك المصلحة مفترضة ولا داعي لإثباتها، لكن الإشكالية هي مصلحة المؤمن له تتعلق بحياة شخص آخر ولابد من دراسة نصوص القانون المدني الأردني للبحث في ذلك.

جاء نص المادة (Y乏) ) "لا يشترط لنفاذ عقد التأمين على حياة الغير موافقته خطيً قبل إبرام العقد فإذا لم تتو افر فيه الأهلية فلا ينفذ عقده إلا بمو افقة من يمثله قانونًا". نلاحظ أن المشرع الأردني وكأنه لم يشترط المصلحة في عقد التأمين على الحياة وإنما اشترط فقط موافقة المؤمن على حياته الخطية قبل إبرام العقد وعلى ذلك فتكون الموافقة الخطية المسبقة شرط لنفاذ العقد لا لصحته حسب رأي المشرع الأردني. ونجد أن المشرع الأردني قد ذكر عبارة لا ينفذ وعلى ذلك فيكون حكم القانون الأردني في عقد التأمين على حياة الغير من غير موافقة الأخير المسبقة الخطية أنه عقد صحيح إلا أنه موقوف النفاذ، والعقد الموقوف لا يرتب آثاره إلا إذا لحقته الإجازة. إلا أن المشرع الأردني حين ذكر عبارة الموافقة المسبقة وكأنه قد عنى بذلك أن هذا العقد لا يجوز أن تلحقه الإجازة، أي وبعبارة أخرى كأن المشرع الأردني أراد أن يرتب له أحكام العقد الباطل، حيث لهيث جاء في المادة (17 1 ) من القانون المدني: "العقد الباطل ما ليس مشروعَّ بأصله ووصفه بأن اختل ركنه أو محله أو الغرض منه أو الشكل الذي فرض القانون لانعقاده ولا يترتب عليه أي أثثر ولا ترد عليه الإجازة". فكيف يكون العقد موقوفتًا ولا تلحقه الإجازة؟ إن هذا النص مأخوذ من القانون المصري الذي جاء في المادة (V00/ ) منه: "يقع باطلاً التأمين على حياة الغير ما لم يوافق 


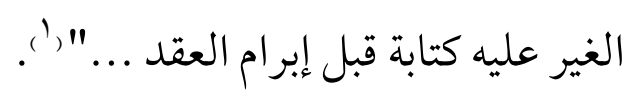

وهذا هو المسلك السليم الذي كان الأجدر بمشرعنا سلو كه حيث أن العقد الباطل لا تلحقه الإجازة ويذلك يتفق مع نص المادة (17 1 ) منه.

فالمشرع المصري متناسق في نصوصه حيث رتب البطلان على تخلف الموافقة الخطية المسبقة، أما مشرعنا فقد رتب الوقف على تخلفها ومنع الملاحقة منها الأمر الذي يفهم من مضمون المادة.

وهذا بديل عن اشتراط المصلحة في عقود التأمين على الحياة، وإن كان هناك خلاف في الفقه المصري حول اشتراط المشرع للمصلحة في عقود التأمين على الحياة أو عدمها، إلا أن الر أي الراجح في الفقه المصري هو عدم اشتراطها بالنسبة لهذه العقود، ولقد كان الأجدر بمشرعنا اشتراط المصلحة لأن الموافقة لا تعد مانعَّ لما تشترط المصلحة التأمينية عادة لدفعه ألا وهو الأخذ بحياة المؤمن على حياته وذلك لتحصيل قيمة التأمين، وكون المشرع رتب جزءاً على ذلك في المادة (ع ؟) لا يمنع من ردع تلك المحاولات هذا فضلاً على أنه بالرجوع إلى نص المادة (ع (9) نجد أنها جاءت على النحو التالي: 1. "يبرأ المؤمن من التزاماته إذا تم التأمين لصالح شخص آخر وتسبب المؤمن له في وفاته أو وقعت الوفاة بتحريض منه".

r. فإذا كان التأمين لصالح شخص غير المؤمن له وتسبب هذا الشخص في وفاة المؤمن له أو وقعت الوفاة بتحريض منه فإنه يحرم من مبلغ التأمين، وإذا كان ما وقع مجرد شروع في إحداث الوفاة كان للمؤمن له الحق في أن يستبدل بالمستفيد شخصكًا آخر. نلاحظ من نص هذه المادة أنها جاءت لتعالج حالة التأمين على حياة المؤمن له نفسه 
و التي يشترط فيها أن يؤول مبلغ التأمين إلى الغير. إن المشرع الأردني لم يرتب أي جزاء على ذلك، وعلى أي حال فإننا هنا أمام القاعدة الفقهية القاضية بأن من استعجل الشيء قبل أوانه

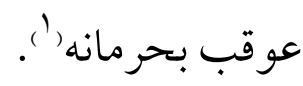

يرى الباحث أن المشرع الأردني لم ينص صراحة على شرط المصلحة في عقود التأمين ولكن القواعد العامة توجب أن يكون هناك مصلحة لأطراف التعاقد باعتبارها من شروط الانعقاد والتي تتمثل في الغرض من التعاقد والباعث على الالتزام لذلك يجب أن يكون موجوداً ومشروعَّ وهي بذلك من أسباب التعاقد.

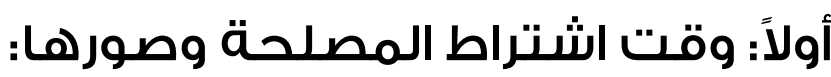

يجب أن تكون المصلحة متوفرة وقت انعقاد العقد لأنها من أسباب التعاقد وهي الغرض من التعاقد. وأن تبقى طوال سريانه حتى يتحقق الخطر المؤمن منه وإذا تخلفت المصلحة عن الانعقاد يبطل العقد لتعلق ذلك بالنظام العام وإذا تخلفت أثناء سريان عقد

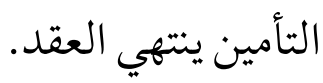
ثنانياً: صور وأثكال المصلحة في عقود التأمين: إن صور وأشكال المصلحة تختلف حسب نوع عقد التأمين كالتالي: المصلحة في عقد التأمين عن الأضرار تتحقق في القيمة المالية التي يخشى عليها من

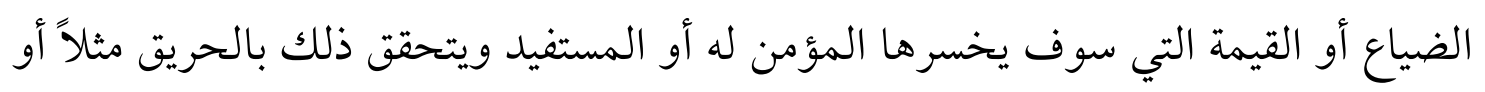

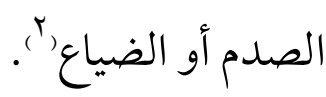
ومن صور المصلحة التعويض عن الضرر والكسب الفائت وهو الخسارة الواقعة

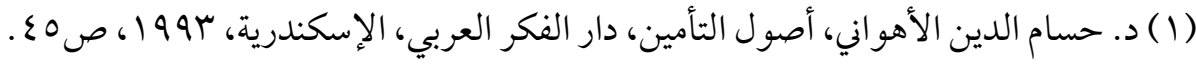

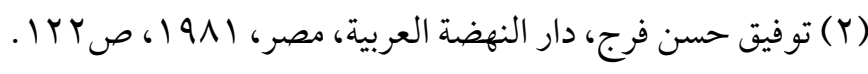

$$
\begin{aligned}
& 0 . \varepsilon
\end{aligned}
$$


على عنصر من عناصر الضرر ويكون التعويض يشمل ما لحق الدائن من خسارة وما ناله من كسب''، وذلك بشرط النص عليها صراحة في عقد التأمين. ويجب تحديد نطاق المصلحة حتى تثبت للمؤمن له ويستحقها من المؤمن.

ولابد أن تتوافر المصلحة بين طرفي العلاقة التعاقدية حتى يسعى كل منهم لتحقيقها

\section{لأنه إذا فقدت المصلحة تحول العقد إلى عقد مقامرة'‘. \\ ثالثاً: طبيعة المصلحة التتأمينية}

إن المصلحة الواجب توافرها هي مصلحة اقتصادية أو مادية على أنه هناك حالتين المصلحة التأمينية فيهما مفترضة الأولى هي حالة تأمين الشخص على حياة شخصه، وأساس افتراضها المنطق، والحالة الثانية هي حالة تأمين الزوج على حياة زوجته أو الزوجة على حياة زوجها وأساس افتراضهاوجود المصلحة فيها هو القانون"

والعبرة في افتراض وجود المصلحة في تلك الحالتين هي أن هاتين الحالتين تخرجان عن الغاية التي جاء من أجلها وهي تحريم المقامرة' وهاتان الحالتان مسمو حتان في عقود التأمين بغض النظر عن قيمة العقد، إلا أن هذان الافتراضان المنطقي والقانوني لا يخرجان عن هذا الحد وبذلك لا يشملان العلاقات العائلية الأخرى، فهذه العلاقات بحاجة لبحث خاص منفصل في ضوء القضايا التي سوف يتم

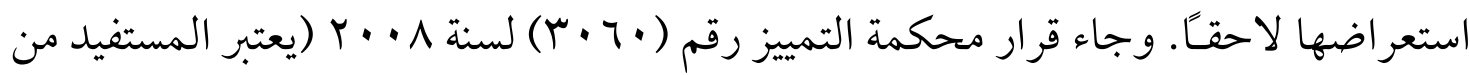

$$
\begin{aligned}
& \text { (1) عبد المنعم البدراوي، مطبعة التقوى، القاهرة، ص0 ـ ا. } \\
& \text { (Y) عبد المنعم البدر اوي، مرجع سابق، ص rع ا . }
\end{aligned}
$$

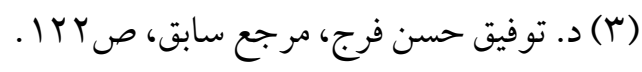

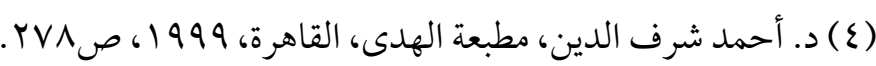

$$
\begin{aligned}
& 0 \cdot 0
\end{aligned}
$$


التأمين صاحب مصلحة في الدعوى وله الحق في مقاضاة شركة التأمين عند تحقق الخطر المؤمن عليه ومن حقه المطالبة بقيمة المبالغ التي تحصل في القضية وعليه فإن للمستفيد الحق في إقامة الدعوى للمطالبة بقيمة الأضرار وتعتبر الخصومة متوفرة. فيما يتعلق بالأولاد القصر وهل يوجد لهم مصلحة في التأمين على حياة والديهم فإنه من الواضح أن الطفل له مصلحة مادية في حياة والديه إذا كانا ملزمين بالإنفاق عليه، أما عن وجود مثل هذا الالنزام فإنها مسألة غير مؤكدة. إلا أنه إذا صدر حكم قضائي يقضي بالإنفاق فإن الطفل القاصر تتحقق له مصلحة في التأمين على الحياة من هو ملزم بالإنفاق عليه من الو الدين وإذا ما قارنا هذا الوضع مع الوضع القائم في الأردن فإننا نجد أن القانون هو مصدر مثل هذا الالتزام بالنسبة للو الد وبعض الأقارب الذين حددهم القانون فالو الد ملزم بالإنفاق على الولد حتى يصل سن يستطيع معها التكسب والعمل، وهو ملزم بالإنفاق على الفتاة حتى تتزوج ما لم تكن موسرة' '. وبناء على ما تقدم فإنه يحق للأولاد التأمين على حياة أبيهم في حدود كونه ملتزماً

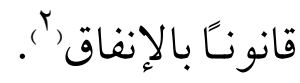

وبذلك فإن القانون الأردني منع الشاب البالغ القادر من التأمين على حياة أبيه حيث لا مصلحة مادية مع الأخذ بعين الاعتبار نص المادة (rع (9) من القانون المدني الأردني. ونأتي الآن إلى الحالة المعاكسة وهي الحالة التي يقوم فيها الأب أو تقوم فيها الأم بالتأمين على حياة الأولاد. فالمعلوم أن الأب لا يملك أي مصلحة في التأمين على حياة أو لاده وذلك لأنه في حالة وفاة الابن أو البنت فإنه ليس هناك أي ضرر يلحق بالو الدين. إلا أنه

\footnotetext{
(1) د. أبو زيد عبد الباقي، المبادئ العامة للتأمين، منشورات الحلبي، بيروت، • 91 1، صع^ب. (r) د. عبد القادر العيسى، التأمين البري في التشريع الأردني، دار الثقافة، 1991 19، ص194. 
جرى قبول عقود التامين التي يبرمها الو الدين على حياة الأبناء في حدود مصاريف الدفن أما فيما يتعدى هذا المبلغ فالتأمين غير جائز وذلك لانعدام المصلحة المادية' '. فيما يتعلق بتأمين صاحب العمل على حياة العاملين لديه، أو العمال على حياة صاحب العمل، فقد عالج الفقه هذه المسائل في العديد من أحكامه فالعامل له مصلحة مادية في حياة صاحب العمل في حدود الراتب الذي يتقاضاه من صاحب العمل ل؟، فيما يتعلق بعقود التأمين التي يبرمها الدائن على حياة مدينه فقد أجاز القضاء الإنجليزي هذا النوع من العقود في العديد من أحكامه ولكن في حدود مبلغ الدين فقط، ولا يجوز أن يتعدى ذلك كون مبلغ الدين يمثل قيمة مصلحة الدائن على حياة مدينه.

وأجاز الفقه أن يكون مبلغ التأمين على حياة المدين أكثر من قيمة الدين شريطة أن لا يتسم بالمقامرة، أي بمعنى آخر أن لا يكون الفرق بين قيمة العقد وقيمة الدين فاحشَّ". السؤال الذي يثور الآن هو ماذا يحدث للدين إذا توفى المدين وقامت شركة التأمين

$$
\text { بدفع مبلغ التعويض للدائن وهو بالطبع مماثل لقيمة الدين المترتب له؟ }
$$
لقد قضت المحاكم في السابق بأن الدين يبقى مرتب في ذمة المدين ويأخذ الدائن

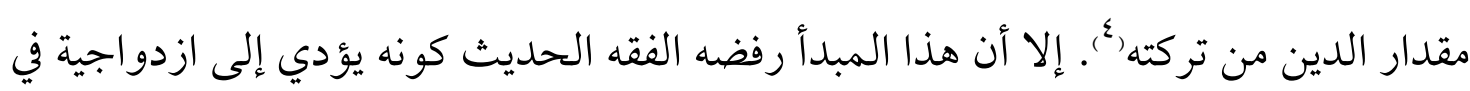
التعويض أي أن الدائن استوفى حقه في تركة المدين كما استوفى مبلغ التعويض، وهذا الأمر مخالف لأبسط مبادئ التأمين القاضية بأنه لا يجوز أن يعوض المؤمن له مرتين عن ذات

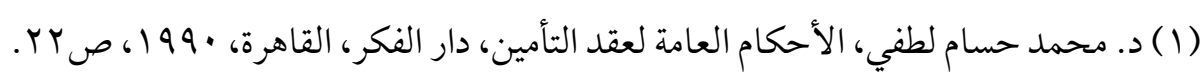

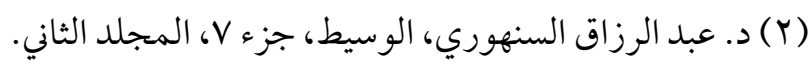

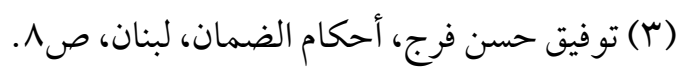

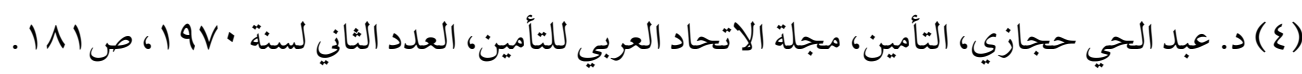


يبقى الآن أن أبحث موضوع مهم تابع لموضوع المصلحة التأمينية وهو ماذا يترتب

على عدم توافر المصلحة التأمينية في عقود التأمين على الحياة؟

في ظل المشرع الأردني لم يشترط المصلحة التأمينية في عقود التأمين على الحياة وإنما اشترط المو افقة الخطية للمؤمن على حياته قبل إبرام العقد، وبالتالي فإن أي عقد تأمين على حياة الغير مع موافقة الغير الخطية هو عقد صحيح نافذ ملزم ومرتب لكافة آثاره. لكن ماذا يترتب على العقد الذي لا توجد به إجازة أو موافقة مسبقة؟ هل هو عقد باطل كما جعله المشرع المصري؟ بالرجوع إلى نصوص القانون الأردني نجد أن المشرع قد اشترط الموافقة للنفاذ أي أنه موقوف إلا أنه عاد ومنع الإجازة. ومعلوم لنا أن الإجازة اللاحقة تلحق العقد الموقوف فكيف للمشرع أن يجعل العقد موقوفـًا ولا يسمح بإجازته لاحقـًا، فعلى ذلك فإن هذا العقد لم ينفذ ولن ينفذ وعلى ذلك أرى أنه يترتب إعادة الأطراف إلى الحالة التي كانت عليها قبل التعاقد وذلك بإعادة أقساط التأمين إلى المؤمن له'بك.

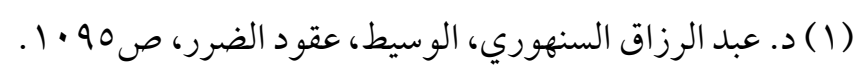

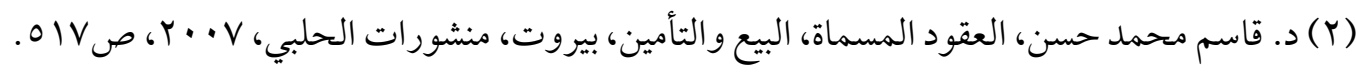
$0 \cdot 1$ 


\section{المبحث الثالث}

\section{شرط المصلحة في عقود التأمين من الأضرار}

يقصد بالتأمين من الأضرار ذلك التأمين الذي يؤمن فيه الشخص نفسه من الأضرار

$$
\text { التي تصبه في ذمته المالية'‘ }
$$

ا. التأمين على الأشياء: وهو التأمين من الأضرار التي تصيب ملكـا للمؤمن له كما لو أمن على سيارة له من الحريق أو السرقة أو الأضرار الأخرى وكذلك التأمين ضد سرقة

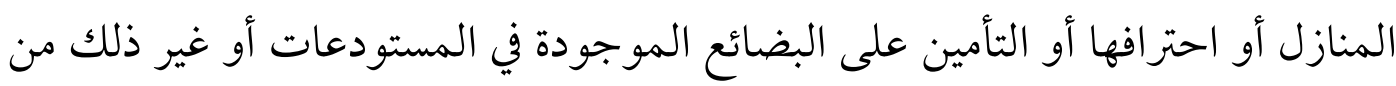
صور التأمين من الأضرار العديدة. r. التأمين من المسؤولية: وهو التأمين الذي يبرمه الشخص ضد الضرر الذي يلحقه في ذمته المالية إذا ما ثبت مسؤولية تجاه طرف آخر وعلى ذلك فيكون في هذا النوع من التأمين أطر اف ثلاثة هي المؤمن، المؤمن له والطرف الثالث الذي يستحق التعويض عند ثبوت المؤمن له. إلا أن هذا النوع من التأمين يتميز عن التأمين مع الاشتراط لمصلحة الغير في أنه هو في الحالة الأولى يبرم المؤمن له التأمين لمصلحته الشخصية لا لمصلحة الغير أي لي لهي أنه هو المستفيد في حالة إيقاعه ضرر بالغير حيث تقوم شركة التأمين بتعويض الطرف الثالث نيابة عن المؤمن له وذلك خلافًَ لحالة الاشتر اط لمصلحة الغير حيث تقوم شركة التأمين بتعويض الطرف الثالث نيابة عن المؤمن له وذلك خلافًَ لحالة الاشتراط لمصلحة الغير التي يكون المستفيد فيها شخصكًا غير المؤمن له. ويختلف التأمين من الأضرار عن التأمين على الأشخاص في نواحي عديدة لا يهمنا في هذا المجال سوى جانب واحد فقط وهو أن التأمين من الأضرار تأمين تعويضي بمعنى أنه 
لابد من وقوع ضرر حتى يتم تعويض المؤمن له أو الشخص الثالث، وذلك بعكس التأمين

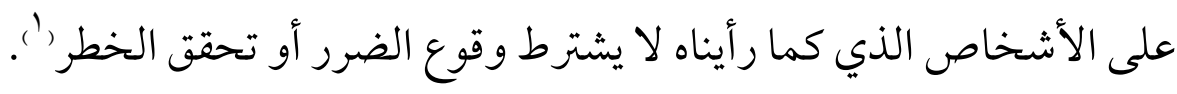

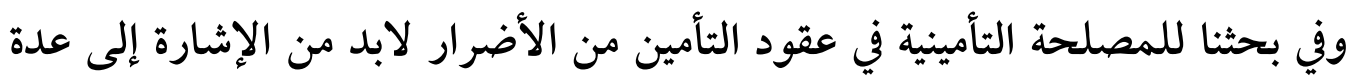

مواضيع أساسية أهمها:

\section{أولاً: طبيعة المصلحة التأمينية وشخص المؤمن له:}

يجيز القانون لأي شخص كان أن يبرم عقد تأمين على ملك الغير أو حتى على

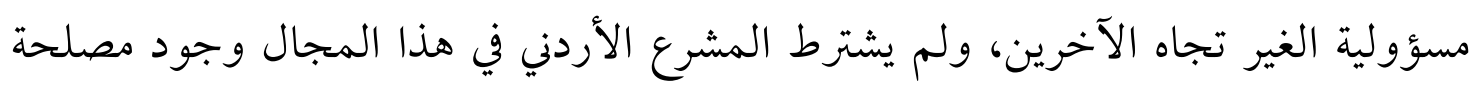
تأمينية للمؤمن له في محل العقد.

إلا أن المشرع الأردني قد عالج موضوع المصلحة التأمينية بطريقة أخرى - وإن كانت

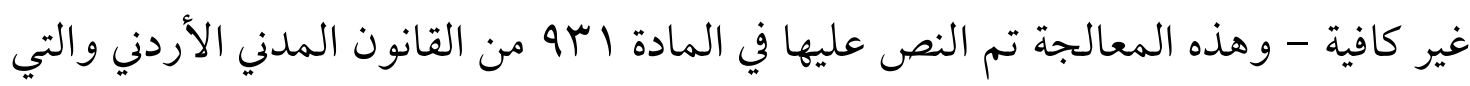

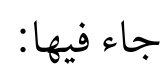

"لا يجوز للمؤمن أن يدفع لغير المتضرر مبلغ التأمين المتفق عليه كله أو بعضه ما دام

$$
\text { المتضرر لم يعوض عن الضرر الذي أصابه". }
$$

وعلى ذلك ففي الحالات التي لا تعد اشتراطكً لمصلحة الغير، وكذلك كتعويض التصن

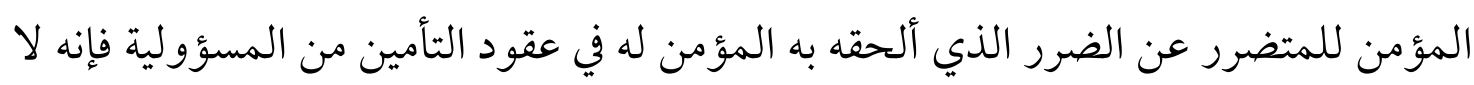

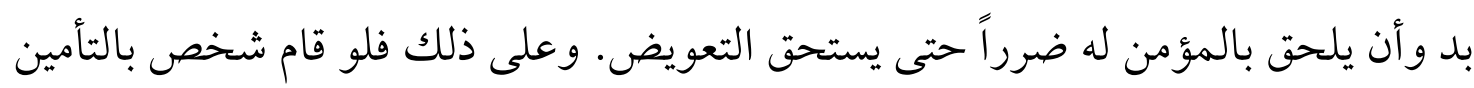

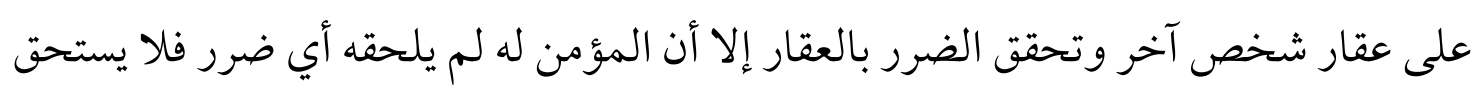

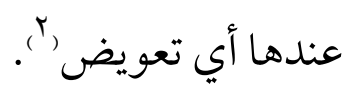

(1) د. محمد علي عرفة، التأمين، مطبعة فؤاد، القاهرة، ص 97.

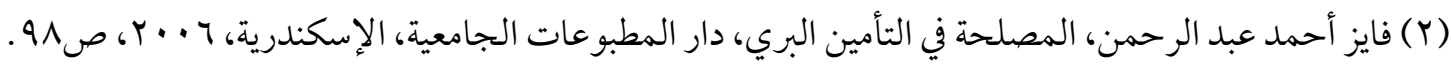


وكأن المشرع الأردني أراد أن يشترط امتلاك المؤمن له مصلحة مادية في الشيء محل التأمين حتى يستحق التعويض المتفق عليه في عقد التأمين. فلا تعويض حيث لا ضرر قد لحق بالمؤمن له حتى ولو تحقق الخطر فلا بد، بعبارة أخرى،

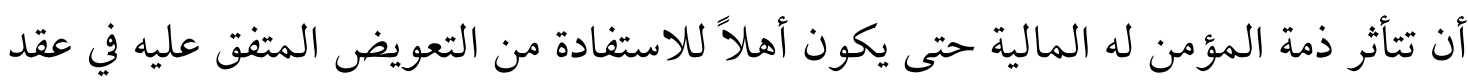
التأمين. لكن التساؤل الذي يثور الآن هو الشخص الذي يملك تلك المصلحة، وعلى ذلك

$$
\text { يستحق التعويض؟ }
$$

لا خلاف على صحة إبرام المالك لعقد التأمين على ملك له، فالمثال البسيط على ذلك، هو إبرام مالك السيارة عقد تأمين ضد جميع الأخطار التي قد تلحق بسيارته. إن هناك فئات عديدة من الأشخاص - إذا ما طبقنا عليها المعيار السابق الذي أوردته و الذي مفاده تأثر ذممهم المالية في حالة تحقق الحادثة المؤمن ضدها في العقد - تملك الحق في إبرام عقود تأمين على أموال ليست ملكتً لها. وهذه الفئات هامة جداً ويخاصة في الأمور التجارية ومن الأمثلة على تلك الحالات ما يلي: الدائن المرتهن الذي يملك الحق في التأمين على المرهون خوفتً من هلاكه وذلك في أنه إذا ما هلك المرهون تأثرت ذمة الدائن المرتهن المالية من جراء ذلك. كذلك بالنسبة للمستأجر فله الحق في إبرام عقد تأمين على العين المستأجرة خاصة وانه ملتزم قانونًا بإعادة العين إلى المالك بإلحاحه التي كانت عليها عند استئجارها وبذلك فإن أي ضرر يلحق بالعين المؤجرة أثناء فترة العقد تكون من مسؤولية المستأجر '.

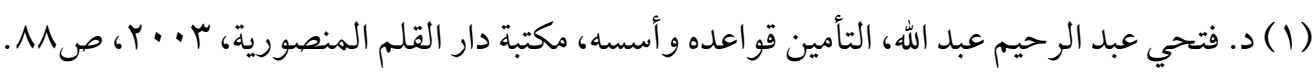




\section{ثانياً: وقت اشتراط المصلحة التأمينية:}

كما ذكرت سابقَّ فإن المشرع الأردني لم يشترط بنص صريح توافر المصلحة التأمينية في عقود التأمين من الأضرار وعلى الأشخاص على حد السواء. وبناء على ذلك فإنه من

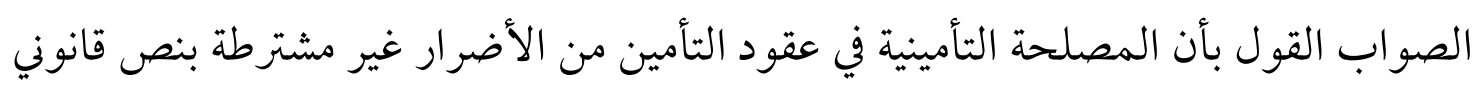

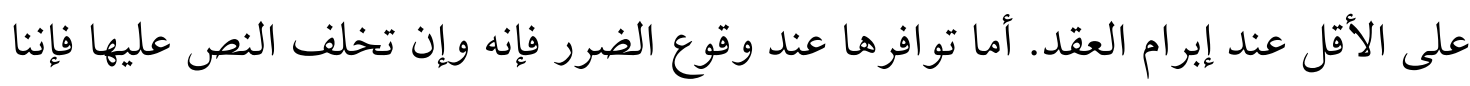

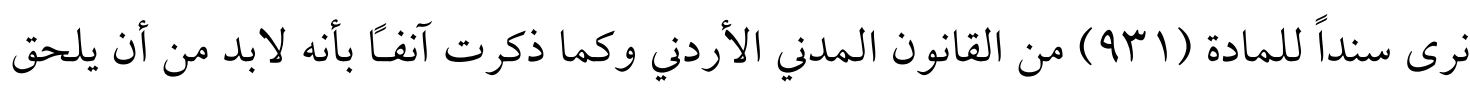

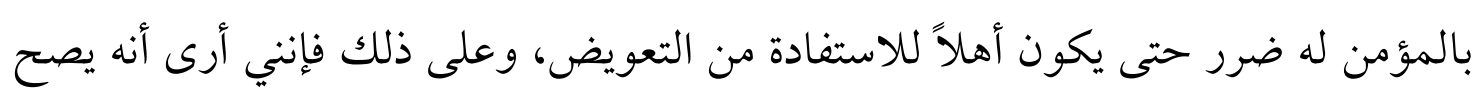

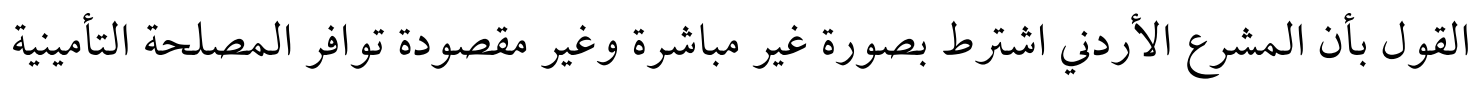
في عقد التأمين من الأضرار عند تحقق الضرر. وجاء قرار محكمة التمييز الأردنية رقم

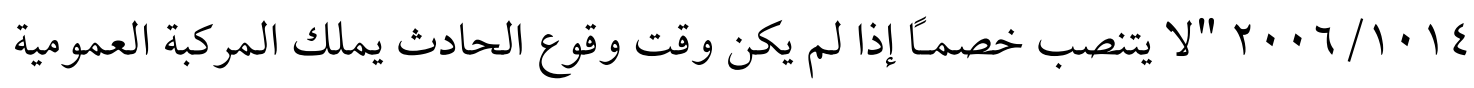

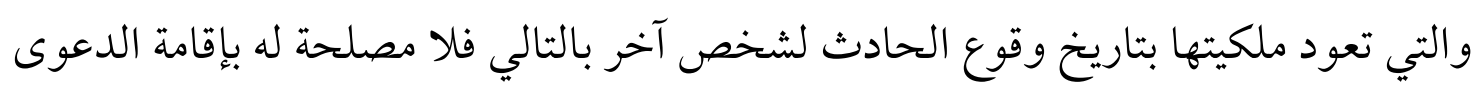
ضد شركة التأمين وليس له صفة لإقامة الدعوى".

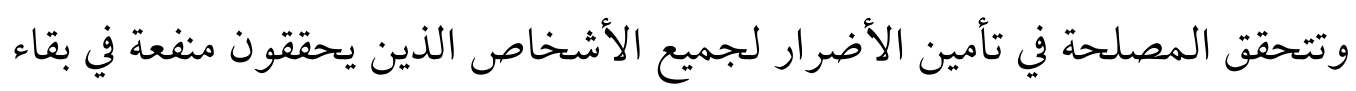

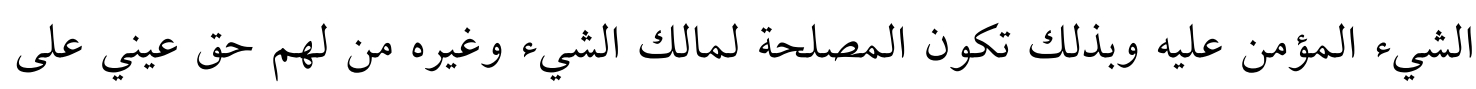

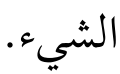

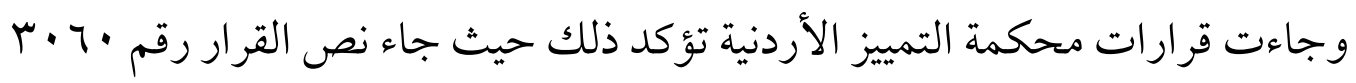

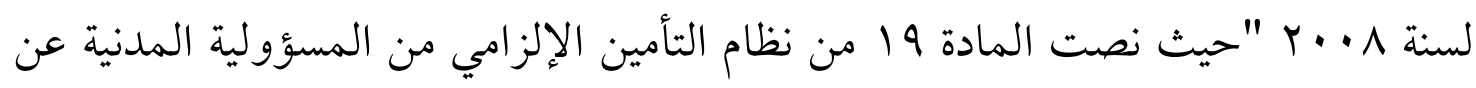

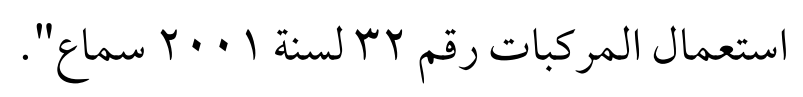

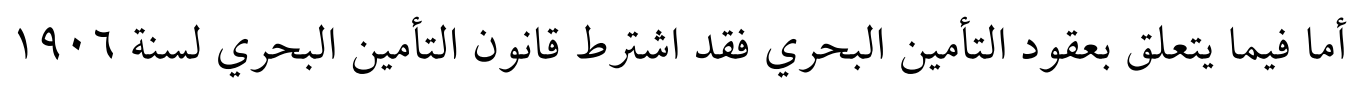
أيضًا تو افر هذه المصلحة عند إبرام العقد.

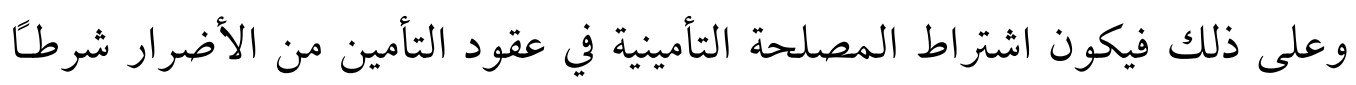


لصحة العقد في القانون حيث رتب المشرع البطلان كجز اءعلى تخلفها. أما بالنسبة لاشتراط تو افر المصلحة عند وقوع الضرر فإنه كون هذه العقود هي عقود

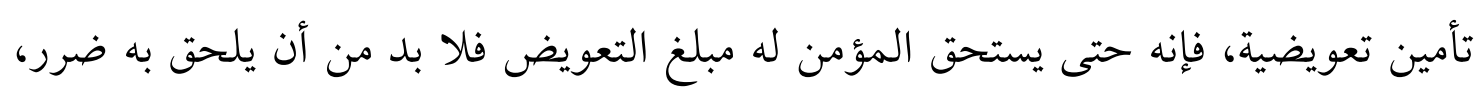
ومقدار هذا الضرر هو قيمة مصلحته في الشيء محل التأمين '‘ '. 


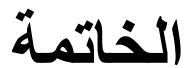

إن موضوع المصلحة التأمينية من المواضع الأساسية والهامة التي عالجتها قوانين

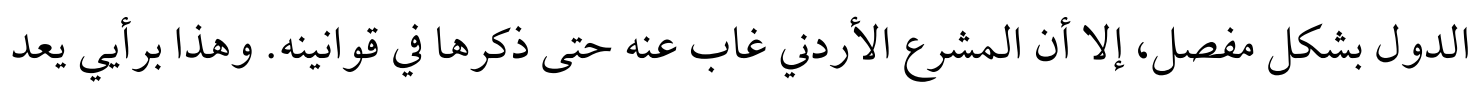

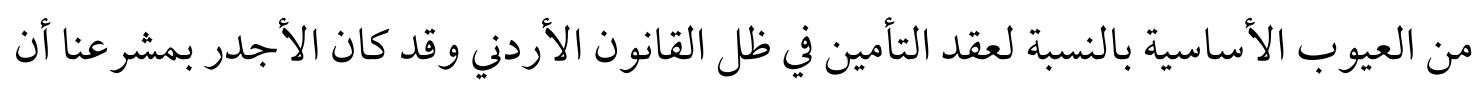
يبحثها بشكل مفصل حتى يتجنب إشكالات سوف تظهر بشكل أكيد في المستقبل، خاصة إذا

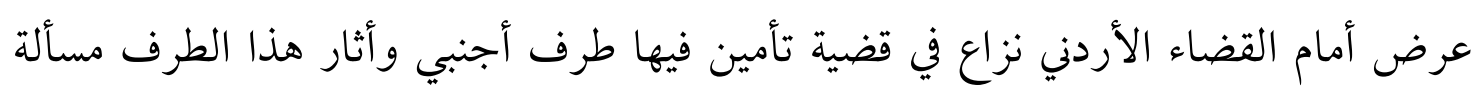

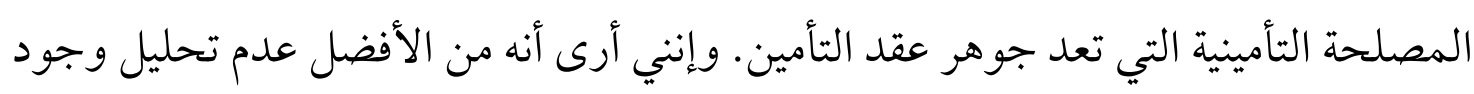

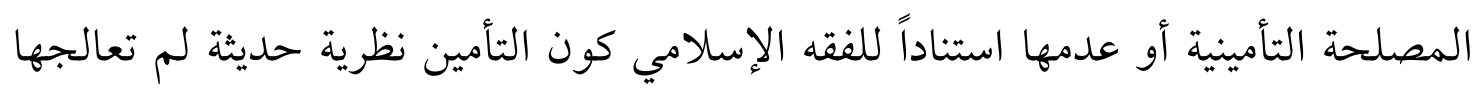

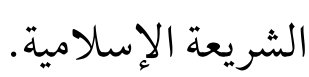

ولقد كان الأجدر بمشرعنا أن يعالج موضوع المصلحة التأمينية بشكل مفصل كما

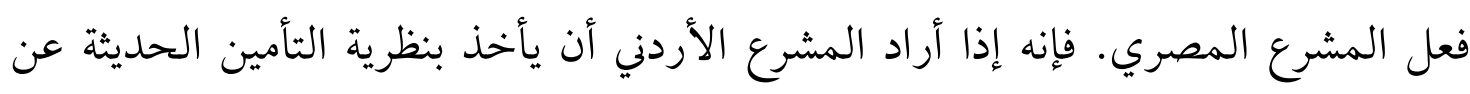

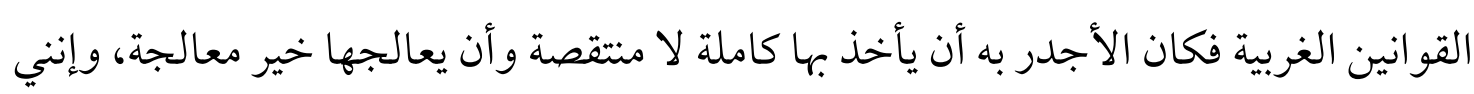

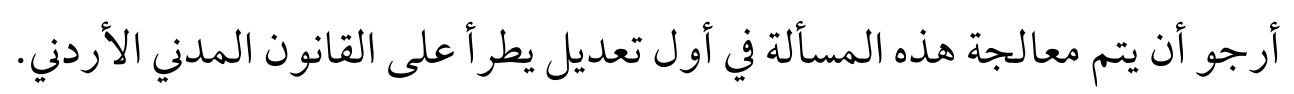

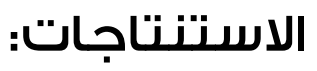

ا. لم ينص المشرع الأردني على شرط وجود المصلحة في عقد التأمين بشكل صريح وإنما

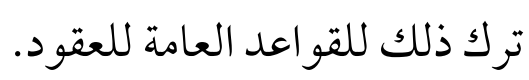

r. r. لم يتطرق المشرع الأردني في تعريفه لعقد التأمين عن صورة التأمين لحال البقاء.

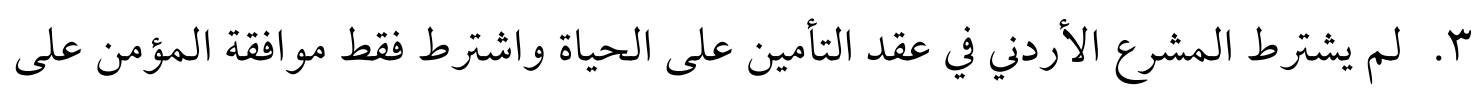
حياته الخطية قبل إبرام العقد وهي شرط لنفاذ العقد.

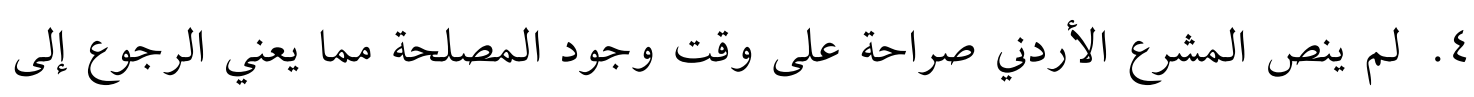

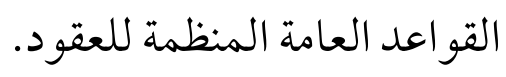


ه. المشرع الأردني وفي المادة البه يشترط أن يلحق بالمؤمن ضرر حتى يتحقق التعويض أو

$$
\text { كان من الغير. }
$$

T. لم ينص المشرع الأردني على المصلحة في التأمين من الأضرار على الأشياء والأشخاص.

\section{التوصيات:}

ا. يوصي الباحث أن ينص المشرع الأردني صراحة على وجود المصلحة في عقود التأمين

$$
\text { حتى تتميز عن غيرها وبالذات المقامرة. }
$$

r. يوصي الباحث النص صراحة على بطلان عقد التأمين على الحياة إذا لم تتم الموافقة مسبقـا وليس عدم نفاذ العقد كون العقد غير النافذ يختلف عن العقد الباطل. r. يوصي الباحث أن يكون شرط المصلحة وقت إبرام العقد ويستمر باستمرار العقد. 


\section{قائمة المصادر والمراجع}

1. أحمد أبو الوفا، نظرية الأحكام في المرافعات، دار الفكر، القاهرة، 1919.

r. أحمد شرف الدين، مطبعة الهدى، القاهرة، 1999.

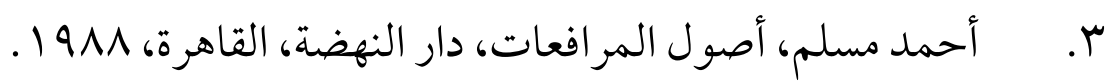

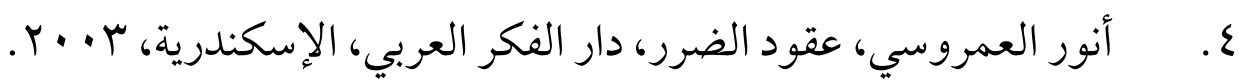

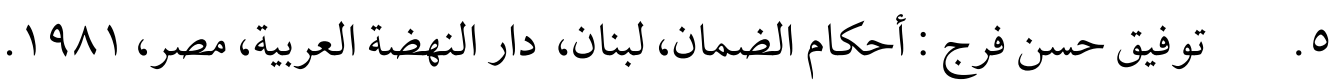

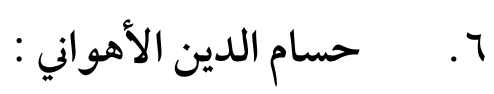

أصول التأمين، دار الفكر العربي، الإسكندرية، سولـ 199 .

المبادئ العامة للتأمين، القاهرة، دار النهضة، 19 أو

V. أبو زيد عبد الباقي، المبادئ العامة للتأمين، منشور ات الحلبي، بيروت، • •191.

1. عبد الحي حجازي، التأمين، مجلة الاتحاد العربي للتأمين، العدد الثاني لسنة • 19 ـ.

$$
9 \text {. عبد الرزاق السنهوري: }
$$

الوسيط في شرح القانون المدني، الجزء السابع، عقود الضرر وعقد التأمين، منشأة

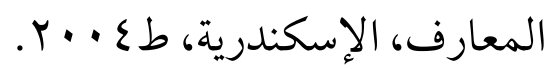

الوسيط، الجزء السابع، دار النهضة العربية، مصر، ع 197. الوسيط، جزء V، المجلد الثاني.

الوسيط، عقود الضرر، الجزء السابع، دار النهضة العربية، مصر، ع79 197.

• ا. عبد القادر العيسى، التأمين البري في التشريع الأردني، دار الثقافة، 1991.

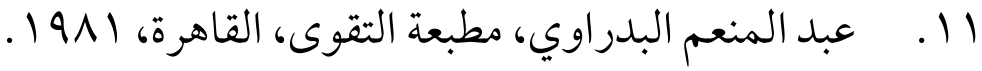

r ا. ايز أحمد عبد الرحمن، المصلحة في التأمين البري، دار المطبوعات الجامعية،

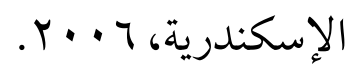


rا ـ فتحي عبد الرحيم عبد الله، التأمين قو اعده وأسسه، مكتبة دار القلم المنصورية، ب . . r. ع ا.قاسم محمد حسن، العقود المسماة، البيع والتأمين، بيروت، منشورات الحلبي،

$$
. r \cdots V
$$

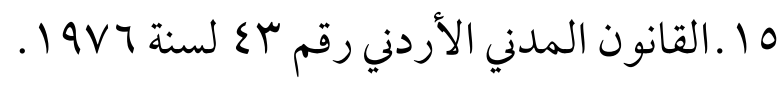
1 القانون المدني المصري.

IV . محمد حسام لطفي، الأحكام العامة لعقد التأمين، دار الفكر، القاهرة، • 199. 11 ـ ـ محمد علي عرفة، التأمين، مطبعة فؤاد، القاهرة. 


\section{فهرس المحتويات}

$\varepsilon q \varepsilon$

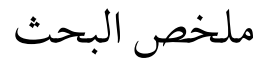

$\{97$

تمهيد :

६१V

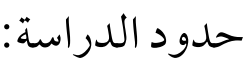

$\varepsilon 9 \vee$

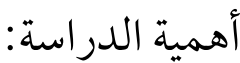

६9V مشكلة الدراسة: - مشاس

६9V

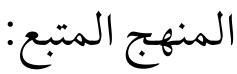

६१९

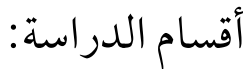

$\varepsilon 9 \wedge$ المبحث الأول نظرية المصلحة التأمينية في عقود التأمين $0 . r$ المبحث الثاني شرط المصلحة في عقود التأمين على الأشخاص. . $0 . \varepsilon$ أو لاً: وقت اشتر اط المصلحة وصورها:

$0 \cdot \varepsilon$ ثانيًا: صور و أشكال المصلحة في عقود التأمين: ...

0.0 ثالثَّ: طبيعة المصلحة التأمينية ..

0.9 المبحث الثالث شرط المصلحة في عقود التأمين من الأضرار .. 01. أولاً: طبيعة المصلحة التأمينية وشخص المؤمن له: 011 ثانيًا: وقت اشتراط المصلحة التأمينية:. 011 
شرط المصلحةفي عقود التأمين

$01 \varepsilon$

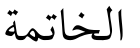

$01 \varepsilon$ الاستنتاجات: - الات

010 التو صيات:

017 قائمة المصادر والمراجع .. 011 فهرس المحتويات 